\title{
It is Useful to Use Plastic Anatomical Models in Teaching Human Anatomy?
}

\author{
IOANA HALMACIU ${ }^{1}$, BOGDAN ANDREI SUCIU1*, CRISTIAN TRAMBITAS ${ }^{1}$, VLAD VUNVULEA ${ }^{1}$, ADRIAN IVANESCUㄹ, \\ ADRIANA CLIPA ${ }^{2}$, PETRU ADASCALITEI ${ }^{3}$, KLARA BRINZANIUC ${ }^{1}$, DECEBAL FODOR ${ }^{1}$ \\ IUniversity of Medicine and Pharmacy Tirgu Mures, Anatomy Discipline, 38 Gheorghe Marinescu Str., 540142,Tirgu Mures, \\ Romania \\ ${ }^{2}$ Ovidius University Constana, Faculty of Medicine, 1 Universitatii Alley, 900470, Constana, Romania \\ ${ }^{3}$ Department of Radiology, University County Hospital, Tirgu Mures, Romania
}

\begin{abstract}
The classical method of teaching human anatomy to students is based on the dissection of human cadavers. Nowadays, there are many ethical controversy regarding the use of human cadavers during anatomy courses. In our study we tried to get undergraduate students' opinion about some different techniques of teaching human anatomy, including the utility of plastic models. We introduced in this study 163 students in the first year of their study at the Faculty of General Medicine from the University of Medicine and Pharmacy, Tirgu Mures. The respondents were asked to fill in a 12-item anonymous questionnaire. Based on the answers provided in the questionnaires we divided the 163 respondents into 2 groups: group A comprising 113 (69.32\%) respondents who found that the best method of teaching anatomy is cadaver dissection and group B comprising 50 (30.67\%) respondents who found that the best method of teaching is not cadaver dissection. Thus, $20(12.26 \%)$ respondents considered that the best method of teaching anatomy is the use of previously dissected and preserved preparations, 4 (2.45\%) indicated the use of plastic models as the best method, 24 (14.72\%) would prefer 3D techniques of image reconstruction and 2 (1.22\%) respondents found that the best method of teaching anatomy is by Microsoft Office PowerPoint presentations. Even though there are still controversial opinions regarding the use of cadaver dissection in teaching and learning human anatomy, especially ethical and psychological ones, cadaver dissection remains the best method of teaching anatomy to undergraduate students in medical schools.
\end{abstract}

Keywords: plastic model, teaching human anatomy

Anatomy is one of the first subjects studied by students in a Medical School. While studying this subject students acquire particularly important knowledge on the subject of macroscopic and microscopic structure of the human body and knowledge necessary for understanding the pathological processes that occur in the human body [1].

About 20 years ago, the only practical way of teaching anatomy was by the dissection of human cadavers. In the last century, the use of human cadavers for teaching and scientific purposes generated disputes over religious and ethical considerations regarding their use in the study of human anatomy. In addition to these ethical issues, in recent years, the purchase of necessary corpses for medical schools has become more and more difficult, hence the emergence of new techniques for teaching anatomy has become necessary. Lately teaching anatomy is based on new, revolutionary techniques like building anatomical models, medical imaging techniques, medical software and 3D techniques of image reconstruction as well as an innovative method of preserving human corpses called plastination [2].

The aim of this paper is to analyze undergraduate students' attitudes towards the use of human cadaveric dissection techniques during a lecture-based anatomy course in medical schools.

\section{Experimental part}

We used the questionnaire method to study the impact of anatomical dissection lessons on students attending our medical school. We introduced in this survey 163 students in the first year of their study at the Faculty of General Medicine of the University of Medicine and Pharmacy, Tirgu

*email : suciubogdanandrei@yahoo.com; Phone: 0040744796343
Mures. The respondents were asked to fill in a 12-item anonymous questionnaire. The questionnaires were distributed to students at the beginning of the second semester of their first year of study, subjects who already attended anatomy courses using cadaveric dissection techniques for training purposes during the first semester.

The first questions were related to general data of the respondents in the study: age, gender, religious affiliation and if they previously had contact with human cadavers or not. We also requested information on their opinion about the use of dissection of cadavers during the anatomy courses, and whether this was in opposition to their religious beliefs or not.

The questionnaire included open-ended and closedended questions on the physical and emotional impact the human cadaveric dissection had during a lecture-based anatomy course on students. These questions referred to the occurrence of physical (nausea, vomiting, irritations) or psychological symptoms (anxiety, fear, insomnia) subsequent to the dissection of cadavers. There were also questions about the transient or permanent character of these symptoms.

At the end of the questionnaire, students were asked to express their opinion about the best way of teaching anatomy. They were asked to choose from five possible choices: cadaver dissection, the use of previously dissected and preserved preparations, Microsoft Office PowerPoint type presentations, 3D techniques of image reconstruction, the use of plastic models. Nowadays there are many plastic models that are used in teaching anatomy in undergraduated students (figs. 1-3).

Statistical Data Analysis was performed by the aid of Microsoft Excel and GraphPad software. We compiled a 


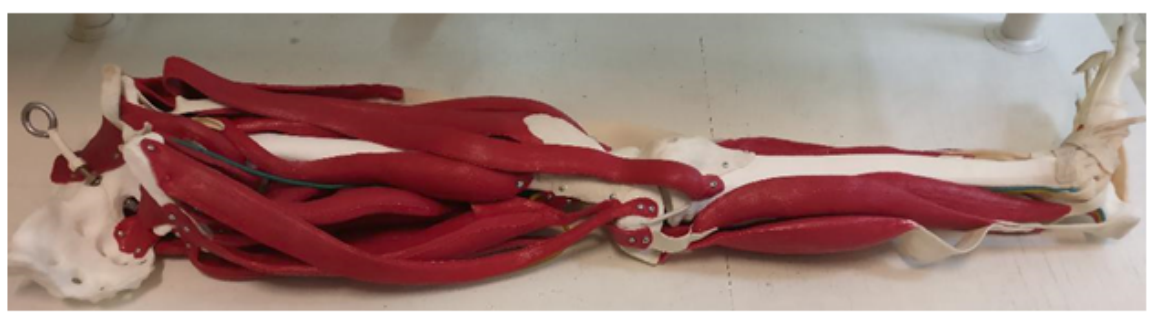

Fig. 1. Plastic anatomic model presenting the muscles of the inferior limb

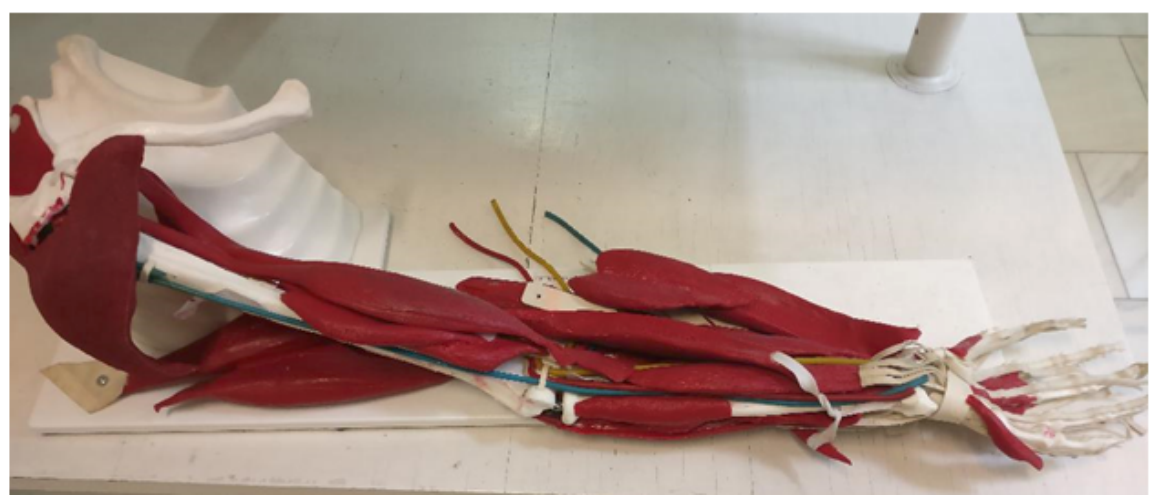

Fig. 2. Plastic anatomic model presenting the muscles of the upper limb

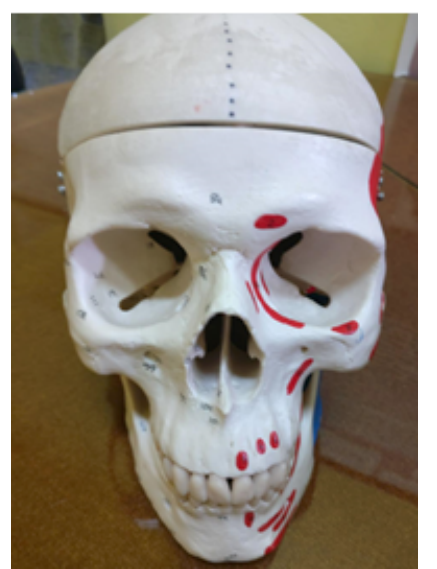

Fig. 3. Plastic anatomic model presenting the bones of the skull data sheet with the tracked parameters for each subject. Data from these records were introduced in Microsoft Excel, this way creating a database. The database created in Microsoft Excel was imported into GraphPad Prism 5.0, and then processed for statistical analysis. We calculated the $p$ value as a statistical parameter (where $p$ represents the statistical probability, so that the observed differences in a medical study should only be the result of accidental incidents; in order to be accepted and statistically significant in case of a medical study p should be less than $0.05)$.

\section{Results and discussions}

The total number of respondents comprised in the survey was 163 undergraduate students attending the Faculty of General Medicine. The mean age of respondents included in the study was 19.89 years (ranging between 18 - 36 years old). The distribution of survey respondents by gender was 111 females (68.09\%) and 52 males (31.9\%) and by religious affiliation 155 Christians (95.09\%), 2 Muslims $(1.22 \%)$ and 6 respondents declared to be non-believers (3.68\%). $70.55 \%$ (115 respondents) stated that they had the first contact with a human corpse during the anatomy course.

Based on the answers provided in the questionnaires we divided the 163 respondents into 2 groups: group $A$ comprising $113(69.32 \%)$ respondents who found that the best method of teaching anatomy is cadaver dissection and group B comprising 50 (30.67\%) respondents who found that the best method of teaching is not cadaver dissection. Thus, $20(12.26 \%)$ respondents considered that the best method of teaching anatomy is the use of previously dissected and preserved preparations, 4 (2.45\%) indicated the use of plastic models as the best method, 24 $(14.72 \%)$ would prefer 3D techniques of image reconstruction and $2(1.22 \%)$ respondents found that the best method of teaching anatomy is by Microsoft Office PowerPoint presentations (fig. 4).

We were also interested in the impact of religious beliefs on the acceptance of cadaver dissection techniques in the educational process and we observed that 8 respondents (5.16\% of those who declared to be Christians) were reluctant about dissecting human corpses based on

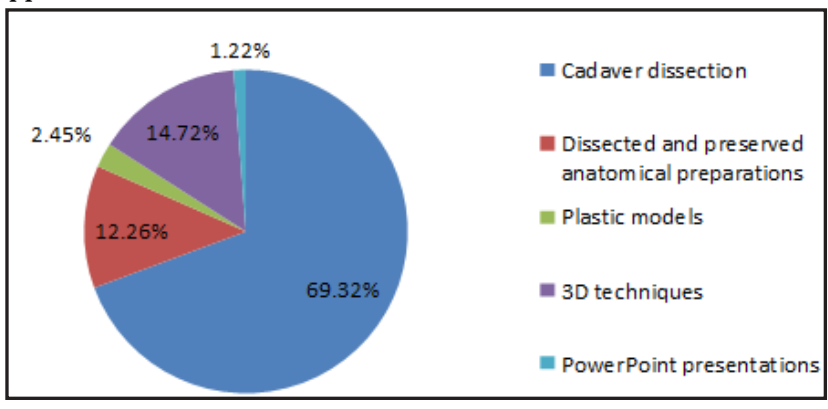

Fig. 4 The best techniques of teaching anatomy according to the respondents comprised in the study

religious grounds, viewpoint which was not expressed by Muslims, but their number was low (only 2 cases).

Respondents comprised in the two different groups (group A in favour and group B against the use of dissection of human cadavers) were studied separately according to the following parameters: previously did not have contact with human cadavers $(68.14 \%$ in group $A$ and $76 \%$ in group $B$ ), the occurrence of physical symptoms (nausea, vomiting, irritating cough) during the first anatomy course (13.27\% in group A and $20 \%$ in group B), whether these physical symptoms persisted during the following lectures too ( $5.30 \%$ in group $A$ and $8 \%$ in group $B$ ), the occurrence of psychological symptoms (anxiety, fear, panic) during the first anatomy course $(6.19 \%$ in group $A$ and $12 \%$ in group B) and whether these psychological symptoms persisted during the following lectures too (1.76\% in group $A$ and $6 \%$ in group $B$ ).

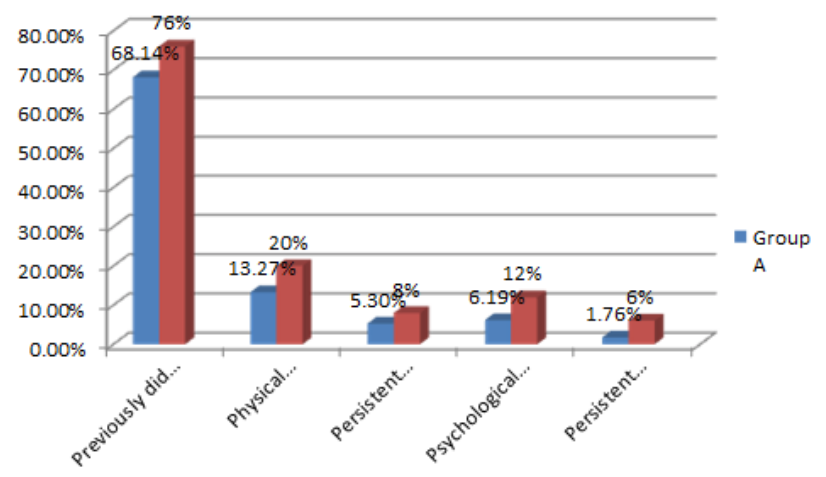

Fig. 5 The incidence of psychosomatic alterations in respondents comprised in the study 
We carried out a statistical data analysis of the results obtained during the survey. In order to find out if there were differences in statistical terms between the two groups regarding their previous contact with human cadavers we used the chi square test. The $p$ value was 0.3101 , showing no statistically significant differences between the two studied groups.

The statistical analysis of the incidence of physical symptoms between the two studied groups was performed by using the chi-square test with Yates correction. This analysis also showed no statistically significant differences between the two groups, $p=0.3880$.

The statistical analysis of the incidence of psychological symptoms between the two studied groups was performed by using the Fischer test. Neither did this case show statistically significant differences between the two groups, $p=0.2211$.

The first evidence of studies on the human body structure appeared more than 2000 years ago, but the first objective scientific data on the dissection of human bodies appeared about 500 years ago [3,4]. Approximately 20 years ago, the only practical way of teaching anatomy was cadaveric dissection. During the last 50 years, extensive discussions arose on ethical aspects regarding the use of human cadavers in the educational process. This is one of the reasons why, in parallel with recent technological development, new techniques have emerged for teaching human anatomy based on 3D anatomy software of image reconstruction techniques.

In the specialty literature, the promoters of the idea that cadaver dissection is the best way of learning abouthuman anatomy consider that the advantage of dissection comes from the fact that it allows the study and recognition of organs inside the body and the topographic recognition of the respective organs. [5] At the same time, dissection allows the real-time presentation of anatomical elements, while computer-based techniques allow the accumulation of artificial images of anatomical elements $[6,7]$.

Extensive debates on ethical issues regarding the donation of human cadavers for educational and scientific purposes resulted in an alarming decrease of the number of cadavers the anatomy departments of medical schools have access to. In this regard, the occurrence of plastination, as a conservation method of dissected cadavers in recent years, presents an outstanding progress in teaching anatomy. This technique is based on injection of substances into body parts that become polymerized at this level. [2] The benefit of the plastination technique is that this allows the preservation of bodies for a longer period (years). Some authors even consider that the benefit of using dissected cadavers preserved by the method of plastination in the educational process is superior compared to the actual cadaveric dissection method performed in front of students [8].

Regardless of ethical issues, the use of cadaver dissection techniques remains a particularly important method of teaching systematic and topographic anatomy. Anatomical dissections are useful for both training undergraduate students in medical schools as well as resident physicians in surgical specialties. $[9,10]$

In the past few decades, the use of cadaver dissections during the anatomy lessons considerably decreased in medical schools. Anatomy software addressed to students and $3 \mathrm{D}$ presentation techniques of anatomical formations are more and more often used.[11] Although in many cases these techniques can not replace the value of the information acquired during anatomical dissections. Many authors consider that cadaver dissection remains the main method of teaching and learning human anatomy [12].
The widespread use of anatomy software is because in recent years the procurement of cadavers became increasingly difficult. The decreasing number of cadavers donated to medical schools can be attributed to the legislation in force and also to possible religious aspects [13].

Using software for teaching anatomy and discarding teaching techniques that include cadaver dissection is actually becoming more common in many European medical schools. The most important argument for abandoning dissection lessons is related to ethical issues. For example, many medical schools in the UK have abandoned the dissection of human cadavers based on ethical issues which is respect for a human being, while many authors consider that the dissection of a human body is a stressful experience for future doctors [14]. The emotional impact the first dissection lesson can have on students is particularly important.

This fact was observed in our survey too, approximately $7.97 \%$ of the respondents declared that after the first dissection lesson showed symptoms of anxiety, fear and panic. But these symptoms were transient in all cases. A plausible explanation for these symptoms is that in most cases this is the first time in these students' lives that they come in contact with the body of a deceased person and become aware of the consequences of death, which leads to anxiety $[15,16]$. In our study $70.55 \%$ of the respondents had their first contact with the body of a deceased person during the anatomy course. These anatomy lessons often remind students of previous deaths cases in their families and implicitly of their and their family members' vulnerability to illness, which induces the sensation of fear in them [17]. Therefore, psychiatric symptoms following dissection lessons underline the importance of psychological impact besides the ethical ones in relation to the use of cadavers during the anatomy lessons.

Physical symptoms like nausea, vomiting and irritating cough students might complain of after a dissection lesson are mainly present due to the irritating effect of formaldehyde used in preservation techniques of corpses. Most physical and psychological symptoms recorded in students during the study were transient and disappeared after the second or third anatomy course, fact also observed by other authors in the speciality literature [18]. However, in case of our study we observed that the prevalence of these symptoms is higher in people who opposed the use of dissection techniques, although the results were not statistically significant. Regarding this issue, the results of our survey support the idea of further use of dissection techniques by students in the learning process.

A particularly important ethical issue that should be addressed during the dissection lessons is respect shown to the cadaver of the deceased person. Dissection techniques should be performed only for scientific or educational purposes. Related to this we should mention that the desecration of graves and human corpses are sanctioned by the law in all European countries. An extremely important aspect is to show due respect to the deceased. There are medical schools in the world which periodically perform religious services to honour the memory of the deceased persons whose cadavers are used at the department of anatomy. A good example of this is the Faculty of Medicine in Pecs, Hungary.

A particularly important aspect is the religious implication of using human cadavers. In this respect, we should mention that all Christian religions sustain the existence of life after death and believe that after the death of an individual the soul remains immortal $[11,19]$. This is 
one more reason to show due respect for the deceased, namely to human cadavers used during the dissection lessons. Despite this ethical-religious aspect in our study we found that only $5.16 \%$ of the respondents, who declared themselves Christians, believe that the use of anatomic dissection techniques is in opposition to their religious beliefs.

From the ethical viewpoint, it is particularly important to highlight how to procure cadavers for the anatomy department of medical schools. The procurement of cadavers must comply with all legal and ethical principles. In the past, there were cases when cadavers for dissection were procured from people with poor social status or criminals and not based on the ethical considerations by the donation of the body after death. Such examples have been recorded in countries like the United States of America or China where corpses of criminals sentenced to death were used for educational purposes. $[20,21]$ These methods are in flagrant contradiction to the principles of medical ethics, which have led to conflicting opinions from the general public regarding the dissection of cadavers for educational purposes [22]. In the UK, the press even reported cases of cadaver traffic in some medical units, which resulted in the decrease of confidence in medical institutions [23].

From the ethical and moral point of view, the donation of cadavers raises two questions. The first question is: why do people choose during their lifetime to donate their bodies after death for educational and scientific purposes? The second question is: how can healthcare professionals persuade someone to donate his/ her own body after death? [24] Many authors consider that donating your own body for educational or scientific purposes is one of the most charitable gestures a person can make. This is his/hers last gift to humanity $[25,26]$. It is clear that the donation of these cadavers must be performed only based on altruistic reasons, without any financial arrangements or gaining other benefits.

Another very important ethical aspect is the selection of cadavers for dissection during the anatomy lessons. In this respect, cadavers should not be used if they can be the source of possible communicable diseases, which can produce sickness in those persons who come into contact with them. This risk can be greatly diminished if the cadavers are properly prepared and formalinized.

Many authors believe that anatomical dissection techniques can be fascinating but also frightening experiences for students of medicine [27]. It can be a fascinating experience due to the student's desire to discover the secrets of the human body. Many students claim that the first dissection lesson they attended was in fact interesting. On the other hand, there are authors who argue that for about $5 \%$ of the students the dissection of a human body is a stressful experience, even causing in some students persistent psychological sequelae [28].

In European Union countries, students do not receive information about the deceased person or causes the death. In some other countries where the majority religion is not Christianity this is different. A good example of this is Thailand. In Thai culture, teachers enjoy great respect, and when a person consents the donation of his body to a medical school, he receives the title of great teacher. This imposes great respect among students, which demonstrates the importance of religion, culture and social values in the use of human cadavers during anatomy lessons [29].

At the same time with the advent of new techniques used for teaching anatomy based on progress in medical informatics (medical software, 3D techniques of image reconstruction), it is more often questioned whether these new techniques have the efficiency of classical dissection techniques in the educational process. Regarding this subject there is still controversy in the literature [30]. It should also be mentioned that while dissecting techniques were validated as suitable methods for learning human anatomy during the last few hundred years, new techniques for teaching anatomy were used only in recent years and not validated yet by time [31,32]. However, after all anatomy teaching techniques must also adapt to technological progress made in recent decades.

The extraordinary development of imaging techniques, medical informatics, the emergence of new technical processes, innovative teaching methods in recent years determined more and more students to prefer them to traditional teaching techniques. In our survey, we found that approximately $30.67 \%$ of the respondents oppose the use of cadaver dissection techniques in teaching human anatomy. A particularly interesting aspect observed in our study was that $15.95 \%$ of the interviewed subjects indicated that from their point of view the best anatomy teaching methods are based on the use of computer techniques and not on techniques based on the use of human cadavers. The existence of a significant number of students who prefer computer-aided teaching during the anatomy courses raises questions regarding the ethical aspects of teaching anatomy based on dissection techniques.

Supporters of modern teaching techniques based on computer-aided methods sustain the superiority of these learning methods. They argue based on ethical controversies related to the dissection of human cadavers, the decreasing number of available cadavers, aesthetics (odour and texture), the toxic effects of substances used for the preservation of cadavers (formaldehyde), the risk of spreading infectious diseases and the psychosocial impact of cadaver dissection on students [5].

\section{Conclusions}

Even though there are still controversial opinions regarding the use of cadaver dissection in teaching and learning human anatomy, especially ethical and psychological ones, cadaver dissection remains the best method of teaching anatomy to undergraduate students in medical schools.

Most psychosomatic disorders which appear after students come into contact with cadaver dissection techniques are not too sever and have a transient character.

Opting for the use cadaver dissection techniques in the learning process during the anatomy course or opposing this is mainly influenced by the students' religious beliefs and not the occurrence of any physical or mental symptoms.

\section{References}

1.KURT E., YURDAKUL SE., ATAC A., Procedia - Social and Behavioral Sciences, 103,2013,p.109-115

2.SUGAND K., ABRAHAMS P., KHURANA A., Anat Sci Educ, 3,2010,nr.2,p.83-93

3.DUSA, FS., BADAU, A., BADAU, D., TRAMBITAS, C., BRINZANIUC, K., Mat.Plast., 54, 2017,no. 4, p. 606-609

4.MURESAN M., MURESAN S., BARA T., BRINZANIUC K., SALA D., SUCIU B., RADU N., Ann. Ital. Chir., 86,2015,p.421-426

5.AZIZ MA., MCKENZIE J C., WILSON J S., COWIE RJ ., AYENI SA., DUNN BK., Anat. Rec., 269,2002,nr.1,p.20-32

6.LOSTUN, G., LOSTUN, A., HAINAROSIE, R., PIETROSANU, C., MANOLESCU, A., BRINZANIUC, K., Rev. Chim.(Bucharest), 67, no. 6, 2016,,p.1183-1185 
7.PAWLINA W., LACHMAN N., Anat. Rec. B New. Anat. 281,2004,nr.1,p.911

8.LATORRE RM., GARCIA-SANZ MP., MORENO M, HERNANDEZ F., GIL F., LOPEZ O., AYALA MD., RAMIREZ G., VAZQUEZ JM., ARENCIBIA A., HENRY RW., J. Vet. Med. Educ., 34,2007,nr.2,p.172-176

9.MIMMS C., Death Enciclopedia, Ed. Orizonturi, Bucuresti, 2006, pp. 241-265

10.TRAMBITAS, C., POP, TS., TRAMBITAS MIRON, AD., DOROBANTU, DC., BRINZNIUC, K., Rev. Chim.(Bucharest), 68 ,no.2, 2017, p.387-389 11.MORAR S., PERJ U DUMBRAVÃ D., CRISTIAN A., Romanian J ournal of Bioethics, 2008, Vol. 6,4:75-83

12.NURUNNABI ASM., ARA S., KHALIL M., KHALIL M., Bangladesh Journal of Bioethics, 2,2011,nr.3,p.10-15

13.ZHANG L., WANG Y., XIAO M., HAN Q., DING J., Anat Sci Educ, 1,2008,nr.2,p.56-59

14.MCLACHLAN JC, BLIGH J, BRADLEY P, SEARLE J., Med Educ 38,2004;nr.4,p.418-424

15.ALT-EPPING B., LOHSE C., VIEBAHN C., STEINBUCHEL N., BENZE G., NAUCK F., BMC Med. Educ. 14,2014,nr.14,p.15, doi: 10.1186/14726920-14-15.

16.BUD V., SUCIU BA., BUTIURCA V., BRINZANIUC K., COPOTOIU R., COPOTOIU C., SIN A., Rom. J. Morphol. Embryol., 54,2013,nr.1,p.115119

17.RIZZOLO LJ ., Anat. Rec. 269,2002,nr.6,p.242-248

18.0'CAROLL RE., JACKSON WS., SINCLAIR DW., Med. Educ., $36,2002, n r .6, p .550-554$
19.J ONES DG., Perspectives on Science and Christian Faith, 47,1995,p.43-51

20.*** Channel 4. The anatomists. www.channel4.co.uk/anatomists 21.SUCIU, BA., HALMACIU, I., BUD, V., COPOTOIU, C., FODOR, D.R.P., TRAMBITAS, C., VUNVULEA, V., MOLNAR, C., BRINZANIUC, K., Mat. Plast. 54, no.3.2017, p.520-522

22.CUTTER B., Rev. Am. Hist., 30,2002,nr.4,p.571-576

23.REGAN DE BERE S., PETERSEN A., Soc. Sci. Med., 63,2006,nr.1,p.7688

24.GUNDERMAN RB., Anat. Sci. Educ., 1,2008,nr.5,p.217-219

25.*** Sukol RB., Hum Pathol 26,1995,nr.7,p.700-705

26.SUCIU BA., HALMACIU I., BUD V., COPOTOIU C., FODOR D., TRAMBITAS, C., GODJA D., VUNVULEA V., MOLNAR C., BRINZANIUC K., Mat. Plast. 54,no.4, 2017, p.626-629

27.WINKELMANN A., GULDNER FH., Cadavers as teachers: the dissecting room experience in Thailand. BMJ 2004; 329(7480): 1455-7 28.FINKELSTEIN P., MATHERS L., Clin. Anat. 3,1990,nr.3,p.219-226

29.GARVEY AM., HICKEY A., CONROY R., Nurse Educ Today., 35,2015,nr.1,p.245-250

30.MCNEILLI W., Anatomy in 3D, J. Bodyw. Mov. Ther., 15, 2011,nr.3,p.375-79

31.OLDER J., Surgeon, 2,2004,nr.2,p.79-90

32.SUCIU BA., PAP Z., DENES L., BRINZANIUC K., COPOTOIU C., PAVAI Z., Rom. J. Morphol. Embryol., 57,2016,nr.2,p.495-500

Manuscript received: 11.05 .2018 